\title{
Fracking tied to cancer-causing chemicals
}

\author{
Cite as: CMAJ 2017 January 16;189:E94-5. doi: 10.1503/cmaj.109-5358
}

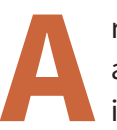
review of chemicals released into air and water by fracking has identified 55 that may cause cancer, including 20 that have been shown to increase the risk of leukemia and lymphoma. The Yale Public Health analysis warns that millions of people living within a mile of fracking wells may have been exposed to these chemicals.

"We urgently need measurements of these and other potentially toxic compounds in communities near these oil and gas operations," says Nicole Deziel, one of the authors of the study.

She argues there's now enough evidence that fracking operations have the potential to increase the risk of childhood leukemia that epidemiological studies should be started alongside exposure measures. "Other cancers may take decades to develop but this is a disease that really deserves attention now because the age of onset is usually two to five years."

Public health research hasn't kept up with the boom in fracking, a method of extracting oil and gas from rock that involves blasting a cocktail of chemicals, sand and water into drilled wells. Because more than a thousand different chemicals are used or released in the process, designing studies has been difficult, Deziel says.

"We wanted to narrow down the list so we know what to go out and measure to confirm whether there's actually contamination or exposure happening," she explains.

The researchers reviewed the evidence of cancer risk for 1117 water contaminants and 143 air pollutants related to fracking - the most extensive analysis of its kind to date.

They discovered huge gaps in knowledge about how these chemicals might affect human health, Deziel says. "More than $80 \%$ lacked enough data to classify whether or not they had the potential to cause cancer."

"We were able to narrow it down to 49 water pollutants and 20 air pollutants that were associated with cancer," or 55 out of 119 unique compounds with enough health data to assess, she says. Of this shortlist, 17 water pollutants and 11 air pollutants or 20 unique compounds had evidence of increased risk of leukemia or lymphoma.

"This study is more evidence that there are a lot of red flags around fracking," says Dr. Courtney Howard, a Yellowknife emergency doctor and board member of the Canadian Association of Physicians for the Environment (CAPE). "We need to increase the levels of research and scrutiny around these projects, with a comprehensive health impact assessment being the responsible thing to do on every single project."
Canada is ramping up fracking to supply the recently approved, multibilliondollar Pacific Northwest Liquid Natural Gas pipeline. British Columbia, which already has more than 7300 fracking wells, plans to increase drilling dramatically to a peak of 800 new wells per year by 2020 .

The Canadian Medical Association passed a motion at its General Council in August calling for assessments of the health and environmental impacts of these projects. In September, CAPE published an open letter urging the same that was endorsed by about 180 health professionals and the Public Health Association of BC. The provinces of Quebec, Newfoundland and Labrador and Nova Scotia have imposed moratoriums on fracking until more evidence about its effects on the environment and health is available.

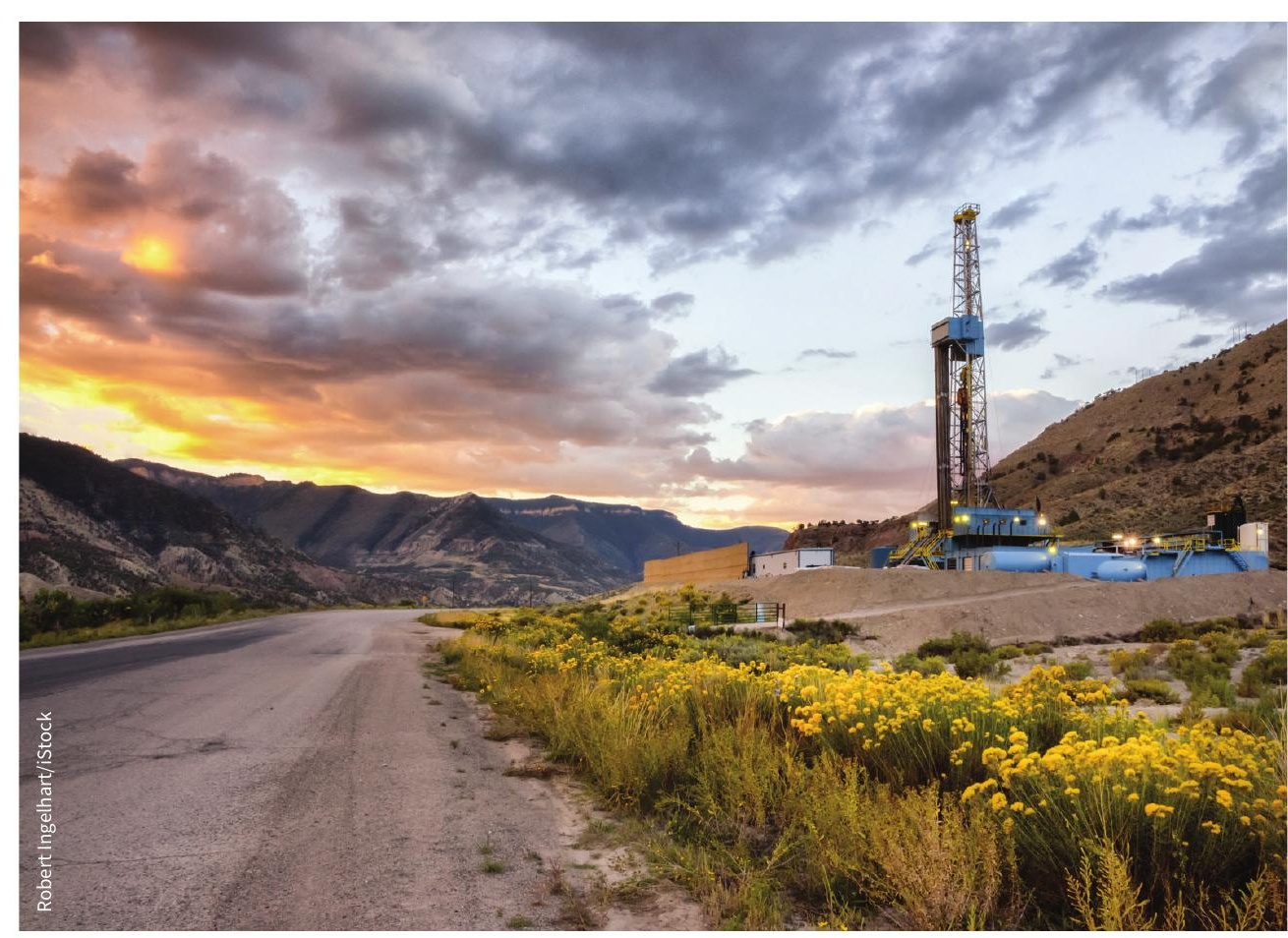

Canadian physicians are urging governments to conduct health impact assessments before greenlighting fracking projects. 
That evidence is increasing, but it's incomplete, says CAPE member Dr. Larry Barzelai, a family physician and assistant professor at the University of British Columbia. He cited a recent PLOS ONE review that showed $84 \%$ of public health studies of fracking indicated increased health risks or negative health outcomes. Meanwhile, 69\% of water quality studies and $87 \%$ of air quality studies show potential or actual contamination from these projects.

"This is like smoking in the 1950s," Barzelai says. "There was a lot of suggestive evidence, but the conclusive stuff came later. I think we're going to get it, maybe in five or 10 years, but it's a question of how much damage is going to be done in the meantime."

Like smoking, political pressure has slowed research into possible harms, he adds. "Our various levels of governments and companies have glommed onto fracking and are reluctant to prove that there's a negative aspect."

According to Howard, some public health physicians in BC "tell me frankly that they were worried they would get fired if they kept working on it."

"Too often we look at the political environment before we look at the evi- dence, and I don't think that's serving our future," she says.

The Canadian Association of Petroleum Producers did not respond to requests for comment. However, the association previously told CMAJ that the shale gas industry is taking steps to allay public health concerns, including funding a regional independent air monitoring system in BC and lobbying for mandatory disclosure of the chemicals used in fracking. Both $B C$ and Alberta made such disclosure mandatory in 2012.

Lauren Vogel, CMAJ 